\title{
A PRESENÇA DA DIFERENÇA NEGRA E INDÍGENA NA EDUCAÇÃO SUPERIOR E O PROCESSO DE RESSIGNIFICAÇÃO DA UNIVERSIDADE BRASILEIRA
}

\author{
THE PRESENCE OF THE BLACK AND INDIGENOUS DIFFERENCE IN HIGHER \\ EDUCATION AND THE PROCESS OF BRAZILIAN UNIVERSITY
}

\section{LA PRESENCIA DE LA DIFERENCIA NEGRA E INDÍGENA EN LA EDUCACIÓN SUPERIOR Y EL PROCESO DE RESIGNIFICACIÓN DE LA UNIVERSIDAD BRASILEÑA}

RESUMO

$\mathrm{O}$ artigo traz uma discussão acerca das tensas relações de poder entre diferentes culturas na universidade. A academia e a ciência tornam-se alvos de problematização, pois são questionadas, sobretudo pela presença ativa de negros e indígenas em seu interior, enquanto invenções eurocentradas que concebiam/concebem as culturas brancas como as únicas fontes e identificações válidas para a produção do conhecimento e da verdade. Focalizamos, primeiramente, os elementos socioculturais constituintes da universidade e, posteriormente, mostramos os impactos da presença de negros e indígenas reivindicando espaços nas universidades. Essa presença como argumentaremos, ressignifica a universidade, pois os saberes/poderes dos grupos negros e indígenas infiltram-se nos saberes hegemônicos, colocando a hegemonia branca em xeque.

PALAVRAS-CHAVE: Educação superior e diversidade racial. Processo de ressignificação e universidade. Diferença negra e indígena.

\begin{abstract}
The article is a discussion about the strained relations of power between different cultures at the university. The academy and science become targets of questioning as they are questioned, especially by the active presence of blacks and indigenous inside while eurocentradas inventions conceived / conceive white cultures as the only sources and valid IDs for the production of knowledge and truth. We focus, first, the constituent elements of socio-cultural university and later show the impacts of the presence of blacks and indigenous people claiming spaces in universities. This presence as we will argue, reframes the university because the knowledge / power of black and indigenous groups infiltrate the hegemonic knowledge, placing the white hegemony in check.
\end{abstract}

KEYWORDS: Higher education and racial diversity. Reframing process and university. Black and indigenous difference.

\section{RESUMEN}

El artículo trae una discusión sobre las tensas relaciones de poder entre diferentes culturas en la universidad. La academia y la ciencia se vuelven albos de problematización, pues son cuestionadas, sobre todo por la presencia activa de negros e indígenas en su interior, mientras invenciones eurocentradas que concebían/conciben las culturas blancas como las únicas fuentes e identificaciones válidas para la producción del conocimiento y de la verdad. Enfocamos, primeramente, los elementos socioculturales constituyentes de la universidad y, posteriormente, mostramos los impactos de la presencia de negros e indígenas reivindicando espacios en las universidades. Esa presencia, como argumentaremos, resignifica a la universidad, pues los saberes/poderes de los grupos negros e indígenas se infiltran en los saberes hegemónicos, poniendo la hegemonía blanca en jaque. PALABRAS CLAVE: Educación superior y diversidad racial. Proceso de resignificación y universidad. Diferencia negra e indígena.

\footnotetext{
${ }^{1}$ Mestre em Educação pela Universidade Católica Dom Bosco; Doutorando na mesma universidade - E-mail: zezao-boni@hotmail.com

${ }^{2}$ Mestre e doutor em Educação pela Universidade do Vale do Rio dos Sinos; Professor da Universidade

Católica Dom Bosco; Bolsista Produtividade - CNPq - E-mail: backes@ucdb.br
}

Recebido em: 02/09/2015 - Aceito em: 15/12/2015.

\begin{tabular}{l|l|l|l|l|l|l} 
(C) Rev. Inter. Educ. Sup. & Campinas, SP & v.1 & n.2 & p.120-135 & out./dez. 2015 & ISSN 2446-9424
\end{tabular}




\section{INTRODUÇÃO}

$\mathrm{O}$ artigo traz uma discussão acerca das tensas relações de poder entre diferentes culturas na universidade. A academia e a ciência tornam-se alvos de problematização, pois são questionadas, sobretudo pela presença ativa de negros e indígenas em seu interior, enquanto invenções eurocentradas que concebiam/concebem as culturas brancas como as únicas fontes e identificações válidas para a produção do conhecimento e da verdade.

Focalizamos, primeiramente, os elementos socioculturais constituintes da universidade e, posteriormente, mostramos os impactos da presença de negros e indígenas reivindicando espaços nas universidades. Essa presença, como argumentaremos, ressignifica a universidade, pois os saberes/poderes dos grupos negros e indígenas se infiltram nos saberes hegemônicos, colocando a hegemonia branca em xeque.

\section{A UNIVERSIDADE MODERNA EM QUESTÃo}

Que sentido tem colocar em questão as coisas a partir da universidade e do conhecimento científico se não colocamos a própria universidade e o conhecimento científico em questão? Em um contexto multi/intercultural de ativismo político-acadêmico, em que negros e indígenas reivindicam espaços nas universidades e na produção do saber acadêmico, a academia e a ciência tornam-se alvos de problematização. "As perspectivas epistémicas subalternas são uma forma de conhecimento que, vindo de baixo, origina uma perspectiva crítica do conhecimento hegemónico nas relações de poder envolvidas" (GROSFOGUEL, 2008, p. 119).

Embora as primeiras universidades tenham surgido na África ${ }^{3}$, nossa referência de universidade é europeia. Considera-se que a noção de universidade mais próxima das culturas ocidentais começa a ser desenvolvida na Europa medieval a partir da fundação da Universidade de Bolonha, na Itália, da Universidade de Paris, na França, e da Universidade de Oxford, na Inglaterra, entre outras ${ }^{4}$ (VARELA, 2013).

A universidade, com suas faculdades, seus graus e titulações acadêmicas é entendida como lugar de destaque para o ensino, os estudos e o conhecimento. O corporativismo acadêmico e os títulos de bacharel, licenciado, mestre e doutor são invenções da universidade medieval europeia.

As universidades estão comprometidas com a formação profissional e intelectual de sujeitos, utilizando-se da autoridade que lhes é conferida, pois “"...] a Universidade é assim

\footnotetext{
${ }^{3}$ Surgiram entre os séculos IX e X a Universidade de Karueein em Fez, no Marrocos, e a Universidade de AlAzhar no Cairo, Egito (VARELA, 2013).

${ }^{4}$ Segundo Correia (1950), “[...] a mais antiga das universidades europeias foi a de Salerno, já existente nos princípios do séc. XI; centro de estudos médicos, inspirados nas obras dos árabes” (p. 293).
}

\begin{tabular}{l|l|l|l|l|l|l} 
(C) Rev. Inter. Educ. Sup. & Campinas, SP & v.1 & n.2 & p.120-135 & out./dez. 2015 & ISSN 2446-9424
\end{tabular} 
autorizada a ter o poder autônomo de criar títulos" (DERRIDA, 1999, p. 8). Essa autonomia é justificada na aristocrática compreensão de que só sábios podem julgar sábios.

A autonomia (administrativa, financeira, acadêmica e didática) da universidade é autorizada pelo Estado e pelas relações hierarquizadas de poder presentes, "[...] de acordo com critérios que não são mais, necessariamente e em última análise, os da competência científica, mas os de uma certa performatividade" (DERRIDA, 1999, p. 87). Portanto, uma autonomia condicionada e limitada pela regulação estatal, mas também pela cultura hegemônica, pelo corporativismo acadêmico, pela branquidade colonizadora institucionalizada, pela sociedade capitalista neoliberal, etc.

O desenvolvimento do conhecimento científico é registrado nas mãos de grupos seletos, sujeitos privilegiados, os sábios cientistas. O modelo universitário aristocrático tornou-se hegemônico nas Américas, baseado nas instituições universitárias europeias. Segundo Trindade (1999), as universidades nas Américas começam a ser implantadas entre os séculos XVI e XVII. As referências europeias de universidades chegaram ao Brasil e foram experimentadas de diferentes modos ao longo da história.

A universidade ocidental foi inventada como o lugar privilegiado dos conhecimentos universais, os saberes acadêmicos são superiorizados, uma significação particular é universalizada. Privilegia-se nessa seleção, apesar das diferenças, uma razão, uma verdade, um conhecimento, uma cultura e uma identidade burguesa, culta, erudita, masculina, branca e europeizada, a partir de referências consagradas de instituições, obras e sujeitos.

Desde suas origens, a academia moderna ${ }^{5}$, envolvida com a formação de uma classe privilegiada e intelectualizada, corresponde aos interesses do capitalismo e do Estado-Nação. O modelo de universidade moderna, fundamentado no iluminismo, na modernidade, na superioridade do conhecimento científico eurocentrado e no ensino associado à pesquisa, ainda inspira as universidades atuais.

A universidade moderna deveria gozar de liberdade financeira, didática, administrativa e científica. O argumento era que "só uma universidade livre e autônoma poderia [...], ser capaz de dar as contribuições que a ciência pode prestar para o desenvolvimento da nação e de seus cidadãos" (PEREIRA, 2009, p. 32). O Estado deveria "[...] respeitar a autonomia administrativo-pedagógica e a liberdade de produção da ciência [para] beneficiar-se do desenvolvimento da ciência, [...] voltada para o bom andamento dos negócios do Estado [...]”' (SILVEIRA e BIANCHETTI, 2013, p. 3).

As universidades são percebidas como preparadoras da vanguarda intelectual, daqueles que serão os sujeitos conscientes condutores do restante da população no caminho

\footnotetext{
${ }^{5}$ Identificamos como universidade e academia moderna as instituições referenciadas nos modelos humboldtiano (alemão) e napoleônico (francês), criados no século XIX (TRINDADE, 1999; PEREIRA, 2009).

\begin{tabular}{l|l|l|l|l|l|l} 
(C) Rev. Inter. Educ. Sup. & Campinas, SP & v.1 & n.2 & p.120-135 & out./dez. 2015 & ISSN 2446-9424
\end{tabular}
} 
certo em meio às mudanças que estão acontecendo na sociedade. Seriam eles os ilustrados que dirigiriam racionalmente os rumos da sociedade.

A instituição universitária seria, na perspectiva moderna, ainda difundida, o lugar onde a verdade deveria ser buscada sem constrangimentos, porque o progresso da ciência (elitista e branca) deveria estar acima dos interesses econômicos e políticos. No entanto, essa instituição está comprometida com uma infinita busca pelo saber/poder, com um projeto de manutenção da sociedade capitalista, admitindo apenas a produção do conhecimento acadêmico como válido e subalternizando os outros.

O capitalismo é uma rede global de poder que congrega dinâmicas econômicas, políticas, culturais e epistêmicas que mantêm o sistema. A ciência - "“[...] neutra, técnica e universal, conferindo à produção do conhecimento caráter de objetividade e matematicidade, fundamentada em uma filosofia não mais especulativa [...]" (SILVEIRA e BIANCHETTI, 2013, p. 4) - está a serviço dos grupos dominantes.

Na modernidade, foi elaborado um modo de produzir conhecimento compatível com as necessidades do capitalismo de controle da natureza e das populações para a apropriação de recursos rentáveis (QUIJANO, 2007). Esse conhecimento eurocentrado foi chamado de racional, imposto como única racionalidade válida e emblema da modernidade. $\mathrm{O}$ conhecimento eurocentrado é constitutivo da economia de mercado.

A sociedade moderna e o Estado-Nação são produtos da cultura burocrática, que nos faz "[...] ver a sociedade como objeto de administração, como uma coleção de tantos 'problemas' a resolver, como 'natureza' a ser 'controlada', 'dominada' e 'melhorada' ou 'refeita', como um alvo legítimo para o 'planejamento social' [...]” (BAUMAN, 1998, p. 37).

A ciência produzida na academia é um aspecto estruturante da sociedade capitalista. A organização social e política estão respaldadas nos discursos científicos. Com a finalidade de garantir a estabilidade, o Estado moderno capitalista, orientado pelo científico planejamento social e pressionado pelas lutas políticas de movimentos da sociedade, mantém a desigualdade dentro de limites para uma inclusão subordinada dos sujeitos.

A identidade nacional, estratégia de homogeneização para garantia de unidade do Estado-Nação moderno, está assentada na etnia/raça dominante. No caso brasileiro, por mais que se enfatize a mistura, as diferenças culturais foram incorporadas, de maneira subordinada, à embranquecida identidade nacional. "A gestão da exclusão deu-se, pois, por via da assimilação prosseguida por uma ampla política cultural orientada para a homogeneização" (SANTOS, 2010, p. 292).

As populações do mundo foram classificadas etnicamente/racialmente pela colonial ciência eurocentrada. A divisão das raças foi cientificamente explicada pelas alvas luzes da razão. "La población de todo el mundo fue clasificada, ante todo, en identidades 'raciales', y dividida entre los dominantes/superiores 'europeos' y los dominados/inferiores 'no-europeos'

\begin{tabular}{l|l|l|l|l|l|l} 
(C) Rev. Inter. Educ. Sup. & Campinas, SP & v.1 & n.2 & p.120-135 & out./dez. 2015 & ISSN 2446-9424
\end{tabular}


(QUIJANO, 2007, p. 120). Essa ciência está relacionada a um elemento constitutivo das relações de poder no capitalismo, a colonialidade (resquícios do colonialismo atualizados). A meta do desenvolvimento científico é chegar ao nível das metrópoles capitalistas.

Gomes (2009) recorda que o racismo científico fez parte da história do conhecimento produzido na universidade:

Não podemos nos esquecer de que foi no contexto científico do final do século XIX e início do século XX que os 'homens de ciência' ajudaram a produzir as pseudoteorias raciais que, naquele momento, atestavam a existência de uma suposta inferioridade e superioridade racial. A ciência serviu, naquele momento, como instrumento de dominação, discriminação e racismo e a universidade foi o principal espaço de divulgação dessas ideias e práticas (p. 423).

Essa produção de atestados de inferioridade (aos negros e indígenas) e de superioridade (aos brancos) marca a trajetória do conhecimento científico. Os efeitos disso ainda são sentidos. Apesar de contestadas, essas teorias reforçaram o racismo, que causa prejuízos simbólicos e materiais às populações negras e indígenas. Portanto, a academia e a sociedade têm uma dívida histórica com esses grupos.

As relações de poder na universidade estão impregnadas de colonialidade e imperialismo epistêmico. "O monologismo e o desenho monotópico global do Ocidente relacionam-se com outras culturas e povos a partir de uma posição de superioridade e são surdos às cosmologias e epistemologias do mundo não-ocidental" (GROSFOGUEL, 2008, p. 137). Todas as realidades passam a ser conhecidas de lugares eurocentrados/ocidentais a partir da lógica científica moderna para serem dominadas, planejadas, governadas e administradas sob essa ótica.

A ciência partilha da herança colonial com a universidade, porque a produção e difusão do conhecimento científico estão baseadas na superiorização deste e da civilização ocidental eurocentrada, tida como moderna, avançada, e considerada o ponto a partir do qual o mundo se torna inteligível.

Os outros saberes, não-acadêmicos, pela academia precisam ser validados (embranquecidos) para terem força de verdade. Ocorre a prática do racismo epistêmico, operação teórica que afirma que os pensadores ocidentais são os únicos capazes de ter acesso à verdade (OLIVEIRA, 2010). Na maioria das vezes, não há comprometimento social. Esse opressor cientificismo ocidental exerce uma grande força na universidade.

A universalidade dos conhecimentos universais foi inventada sobre uma particularidade eurocentrada (LANDER, 2005). Ocorre a "[...] invisibilização de formas de opressão e de resistência e dos atores que as protagonizam, em nome de concepções eurocêntricas de universalidade dos direitos, cidadania e democracia" (SANTOS, 2003, p. 66). Os modelos científicos e sociopolíticos eurocêntricos, supostamente universais, são baseados em formas de dominações econômicas e culturais, porque impostos sob uma perspectiva colonizadora que os considera ideais a toda e qualquer sociedade humana para ingressar na ordem moderna.

A epistemologia moderna que fundamenta a universidade é um ponto de vista parcial que se apresenta como não sendo um ponto de vista parcial (GROSFOGUEL, 2008),

\begin{tabular}{l|l|l|l|l|l|l} 
(C) Rev. Inter. Educ. Sup. & Campinas, SP & v.1 & n.2 & p.120-135 & out./dez. 2015 & ISSN 2446-9424
\end{tabular}


porque se disfarçou de universal. Esse ponto de vista parcial (eurocentrado) é representado como se estivesse acima de todos os outros.

Entretanto, todo conhecimento é atravessado pelas relações socioculturais e de poder, porque parte de sujeitos, portanto, todo conhecimento é parcial. Buscamos compreender e tentam nos compreender sempre a partir de uma posição, mesmo quando a intenção é de neutralidade ou imparcialidade.

Os saberes hegemônicos conclamam a universalidade, exercendo um imperialismo epistêmico ao imporem a supremacia branca/eurocêntrica. "Nenhuma cultura no mundo permaneceu intacta perante a modernidade europeia. Não há, em absoluto, como estar fora deste sistema" (GROSFOGUEL, 2008, p. 137). O eurocentrismo refere-se a uma perspectiva produzida ao longo de séculos de domínio e de hegemonia da branquidade colonial, e essa relação de poder foi naturalizada como se desde sempre existisse.

A Europa aparece, por vezes, representada como o centro mundial do capitalismo, que pela missão colonizadora iniciou a expansão da civilização, do conhecimento, do progresso e da cultura. Munanga (1999), ironicamente, comenta: "o reconhecimento de uma perfeita origem europeia é colocado como condição para ingressar na milícia branca” (p. 33).

A branquidade é uma invenção provocada pelos contatos dos europeus com outros povos não-europeus. Aproveitou-se o sentido de branco da simbologia das cores no ocidente cristão, uma particularidade difundida como se fosse universal, que remete às virtudes, ao bem, à vida, à bondade, ao sucesso, à pureza e à sabedoria. "A branquidade é um lugar de vantagem estrutural nas sociedades estruturadas na dominação racial" (FRANKENBERG, 2004, p. 312).

A branquidade colonizadora tornou-se o modelo hegemônico de humanidade, a localização cultural dominante de onde se produz o conhecimento científico. No entanto, na maioria das vezes, essa localização encontra-se camuflada nos rituais acadêmicos e na normalidade sociocultural. Hierarquias étnico-raciais, de gênero e culturais eurocentradas privilegiaram os homens brancos e cristãos e o patriarcado.

As instituições acadêmicas elaboraram teorias científicas para a inferiorização dos povos não-europeus. "Através das ciências humanas, transformadas em disciplinas, cria-se um enorme dispositivo de normalização que, como tal, é simultaneamente qualificador e desqualificador" (SANTOS, 2010, p. 281).

Os sentidos inventados para as raças/etnias humanas pela colonial ciência eurocentrada produziram hierarquias. "La escalera de gradación entre el 'blanco' de la 'raza blanca' y cada uno de los otros 'colores' de la piel, fue asumida como una gradación entre lo superior y lo inferior en la clasificación social "racial'" (QUIJANO, 2007, p. 120). As relações de dominação racial herdadas da experiência colonial têm consequências materiais, sociais, culturais e epistêmicas ao justificarem formas de exploração e opressão. A economia está entrelaçada com a cultura e o conhecimento científico.

A ciência e os cientistas estão frequentemente do lado das forças dominantes, pois recebem benefícios e privilégios; em contrapartida, com suas verdades, podem aumentar o poder dos poderosos. Processos de dominação, bombas atômicas, holocausto, eugenia,

\begin{tabular}{l|l|l|l|l|l|l} 
(C) Rev. Inter. Educ. Sup. & Campinas, SP & v.1 & n.2 & p.120-135 & out./dez. 2015 & ISSN 2446-9424
\end{tabular}


ameaça nuclear, avanços nas indústrias bélicas, da guerra e da morte, mas também ideias de liberdade, solidariedade, justiça social, igualdade e democracia, entre outras, partiram da racionalidade moderna. Essa racionalidade é hegemônica na academia e na sociedade.

A hegemonia da racionalidade moderna é perpetuada por sucessivos epistemicídios cometidos contra os conhecimentos rivais que representam uma ameaça à sua universalidade. "E como estes conhecimentos foram sempre formas de racionalidade constitutivas de identidades e diferenças socialmente constituídas, os epistemicídios redundaram sempre em identicídios" (SANTOS, 2010, p. 313). A diferença é conhecida por um conhecimento que não reconhece sua legitimidade. A pretensão científica é a de conhecer para governar sob o domínio da ciência.

Bauman (1998), em sua análise da relação entre a modernidade e o holocausto, diz: "o Holocausto foi um choque único entre as velhas tensões que a modernidade ignorou, negligenciou ou não conseguiu resolver e os poderosos instrumentos de ação racional e efetiva que o próprio desenvolvimento moderno fez surgir" (p. 16). Os elementos que tornaram o holocausto e as bombas atômicas possíveis continuam presentes de maneira atualizada.

A racionalidade moderna continua promovendo extermínios físicos e epistemicídios favoráveis ao domínio de uma classe, gênero/sexualidade, raça/etnia, dos em vantagem na economia e nas hierarquias socioculturais: "não se fez o suficiente depois do Holocausto para sondar o potencial medonho desses fatores e menos ainda para impedir seus efeitos potencialmente aterradores" (BAUMAN, 1998, p. 17).

A "civilizada" sociedade moderna, cientificamente orientada, produziu discriminações, preconceitos, racismo, fome, desigualdades e indiferença ao sofrimento alheio. Escreve Bauman (1998): "[...] os horrores do genocídio [do holocausto] ficarão virtualmente indistinguíveis de outros sofrimentos que a sociedade moderna sem dúvida gera diariamente e de forma abundante" (p. 24). Em nossa sociedade, como no holocausto, por vezes, a violência é autorizada e as vítimas da violência são desumanizadas. Normalizamos a opressão e as práticas de violência.

A reflexão ética, muitas vezes, não acompanha os avanços científicos e tecnológicos ou é sobrepujada pelos interesses políticos, econômicos e individualistas. Bauman (1998) alerta que o julgamento moral é exterior à ação e é guiado por critérios diferentes daqueles que guiam e moldam a ação. Os poderes e saberes hegemônicos estabelecem o que é certo, confortando-nos ou indignando-nos. Outros poderes e saberes são criados para enfrentá-los e contestá-los.

Nos processos de transformação social, de ressignificação da universidade e do conhecimento científico, o Estado torna-se um importante espaço de reivindicações de ações institucionais, legislações e políticas públicas específicas. Necessitamos de condições e de lugares onde outras racionalidades possam emergir e ser referências. "Trata-se de uma atividade que requer o reconhecimento de que todas as epistemologias são políticas; portanto, o saber, mais do que uma adequação entre intelecto e realidade, é uma operação de poder [...]" (BACKES e NASCIMENTO, 2011, p. 27). 
A maior presença de acadêmicos negros e indígenas na Educação Superior, proporcionada pelo ativismo de movimentos sociais negros e indígenas e pelas políticas de ação afirmativa (principalmente as cotas), afetam as universidades brasileiras. Negros e indígenas vêm, aos poucos, provocando um processo de ressignificação da academia.

\section{O IMPACTO DA PRESENÇA DA DIFERENÇA NEGRA E INDÍGENA NA UNIVERSIDADE BRASILEIRA}

A instituição universitária convive com as desigualdades, por isso, há ainda poucos estudantes, pesquisadores e professores universitários negros e indígenas. A Educação Superior, denominação bem sugestiva de como arrogantemente está posicionada em relação a outras modalidades da escolarização, ainda representa para negros e indígenas uma trajetória permeada por tensões, conflitos e negociações.

O aumento das pesquisas que tratam das relações étnico-raciais no Brasil vincula-se à luta de negros e indígenas, enfatizando suas demandas e dando visibilidade ao racismo e aos privilégios do branco resultantes de desigualdades produzidas historicamente: "[...] ser branco no Brasil é ter a pele relativamente clara, funcionando como uma espécie de senha visual e silenciosa para entrar em lugares de acesso restrito" (SOVIK, 2005, p. 171).

No nosso país, é possível reconhecer-se como resultado de uma mistura, mas tornase relevante questionar a ideia de que num país de mestiços está tudo tranquilo no que se refere às relações étnico-raciais. "É preciso enfrentar a versão conservadora da mestiçagem" (SOVIK, 2005, p. 172).

A maior presença de negros e indígenas na academia começa a abalar a torre de observação onde a universidade, muitas vezes, pretende localizar-se para analisar sem ser analisada e percebida como étnica, racial, política e culturalmente enviesada. Essa "[...] torre de marfim pode ser menos um refúgio do que está acontecendo 'lá embaixo' do que um posto de observação privilegiado" (SOVIK, 2005, p. 161). Ativistas e movimentos indígenas e negros estão cada vez mais atuantes nas universidades.

Em uma Educação Superior que continua sendo um lugar predominantemente de brancos, os negros e índios mostram os seus modos de ser e contestam os estereótipos inventados para inferiorizar suas identidades. Marcam suas diferenças culturais na academia expondo outros significados, práticas e conhecimentos. Apesar de ainda haver uma resistência à inclusão da diferença negra e indígena por meio de ações afirmativas, o mérito está sendo questionado como critério de ingresso.

O mérito é acionado para desqualificar as políticas que buscam a promoção da igualdade, converter exceção em regra e dar um glamour ao indivíduo (independentemente das circunstâncias) bem-sucedido. Não existe mérito nas desigualdades. Há sujeitos, de 
alguma forma, privilegiados nas/pelas hierarquias socioculturais enquanto outros são menosprezados.

Os negros, bem como os indígenas, procuram na formação universitária uma preparação profissional acadêmica e uma melhor inserção na sociedade. Ao ingressarem em uma faculdade, negros e índios mostram para a nossa sociedade racista que são capazes. Recusam-se a dobrar-se aos discursos coloniais ${ }^{6}$, ainda difundidos de maneira sutil e atualizada, que afirmam serem sujeitos incapazes disso. Eles afetam outros sujeitos nas suas comunidades, e "essa intervenção se dá, na maioria das vezes, de forma a demonstrar aos demais sujeitos da comunidade que eles também podem ter acesso à universidade" (SANTANA, 2010, p. 118).

Santana (2010), em seu estudo sobre os sujeitos negros cotistas, observa que, "[...] ao atribuírem suas identidades à 'capacidade', esses sujeitos cotistas estão produzindo um processo de estranhamento em relação à naturalização da inferioridade criada na modernidade colonial" (p. 112). Nesse sentido, os sujeitos negros estão dizendo, em resposta à sociedade racista, que são inteligentes e não são inferiores.

O aumento do acesso e permanência dos negros e indígenas na universidade proporciona ao ambiente a convivência produtiva com as diferenças por estes trazidas, tornando possível a criação de outras narrativas acerca de suas identidades étnicas/raciais. Trata-se de narrativas que podem servir para luta contra o racismo e as desigualdades. "Essa resistência funciona como um contradiscurso, que está localizado no terreno da representação e do significado" (SANTANA, 2010, p. 118).

Dos lugares que ocupam nos ambientes universitários e nas relações de poder, acadêmicos negros têm contribuído na produção de significados contra-hegemônicos em busca da igualdade racial. Estudantes, pesquisadores e professores negros articulam militância política e trabalho acadêmico, fundamentados em diferentes referenciais socioculturais e nas suas próprias vivências das relações étnico-raciais.

\begin{abstract}
Um dos aspectos positivos desta inserção dos negros no meio acadêmico enquanto docentes é o fato de atuarem como sujeitos de seu próprio conhecimento científico e ocupar lugar de destaque no cenário acadêmico local e nacional, nas associações de pesquisa, na formação de professores e em órgão de gestão governamental (nacional, estaduais e municipais), o que tem proporcionado a produção de um tipo de conhecimento diferente do então produzido nas universidades brasileiras (OLIVEIRA, 2011, p. 163).
\end{abstract}

Universitários negros vão ao encontro dos movimentos sociais e vice-versa. Também se articulam na academia, criaram a Associação Brasileira de Pesquisadores Negros

\footnotetext{
${ }^{6}$ Segundo Bhabha (1998), esse discurso "é uma forma de discurso crucial para uma ligação de uma série de diferenças e discriminações que embasam as práticas discursivas e políticas da hierarquização racial e cultural"
} (p. 107).

\begin{tabular}{l|l|l|l|l|l|l} 
(C) Rev. Inter. Educ. Sup. & Campinas, SP & v.1 & n.2 & p.120-135 & out./dez. 2015 & ISSN 2446-9424
\end{tabular}


(ABPN) e os Núcleos de Estudos Afro-Brasileiros (NEABs) e ocupam posições em diferentes instâncias de tomadas de decisões institucionais. Desafiam a universidade e o Estado a implementarem políticas de ação afirmativa.

Gomes (2009) lembra-nos de que os intelectuais negros na universidade têm posturas diferentes. Nem todos desempenham atitudes militantes e ativistas na universidade. Uns têm mais aproximação com os movimentos sociais, e outros não têm ou não têm tanta. Há aqueles que têm maior reconhecimento acadêmico, e outros nem tanto.

Intelectuais negros na academia contrariam a ideia de neutralidade do conhecimento científico, porque fazem leituras das realidades orientadas pela luta dos afrodescendentes no Brasil. "Não mais um olhar distanciado e neutro sobre o fenômeno do racismo e das desigualdades raciais, mas, sim, uma análise e leitura crítica de alguém que os vivencia na sua trajetória pessoal e coletiva, inclusive nos meios acadêmicos” (GOMES, 2009, p. 421).

Pesquisadores negros questionam a hegemonia da brancura e o eurocentrismo nas ciências sociais. "O papel dos intelectuais negros têm sido indagar a produção do conhecimento acadêmico e o lugar ocupado pelo 'outro', pelo diferente e pelas diferenças" (GOMES, 2009, p. 421).

A investigação das identidades brancas por pesquisadores negros subverte o hábito hegemônico do acadêmico branco de analisar os subalternizados ou os não-brancos. Também possibilita percebermos suas presenças nas relações étnico-raciais, desnaturalizando-as e colocando-as em questão para analisar as significações, a colonialidade e os efeitos dos poderes implicados. "Além disso, a produção acadêmica, dos autores negros, tem contribuído para construção do branco antirracista" (CARDOSO, 2014, p. 121).

O conceito de raça começou a ser debatido com mais força no contexto acadêmico com os pesquisadores negros. Os intelectuais negros enfatizam a importância de ainda discutirmos raça, por conta do potencial político desse conceito para o combate ao racismo, expondo que vivemos ainda numa sociedade racializada pelas "[...] interpretações que recaem sobre os sinais diacríticos inscritos no corpo negro, os intelectuais negros re-politizam a raça e re-semantizam-na" (GOMES, 2009, p. 421).

Assim como os acadêmicos negros, os acadêmicos indígenas também questionam a universidade branca. Eles têm interesse "[...] pelo saber das universidades, não só para aprender com os docentes dessas instituições, mas para mostrar-lhes o valor da cultura, língua, cosmologia e saber indígenas" (CHAMORRO, 2009, p. 16-17). Os índios almejam apropriar-se da academia para subvertê-la, conquistando espaços e transgredindo o confinamento em reservas imposto pelos brancos. Acerca dessa presença indígena, Benites (2009a), intelectual kaiowá, afirma: "é preciso afirmar nossa visão, para, dessa forma, fortalecer nossa cultura e nosso povo" (p. 29). A universidade também é o lugar dos 
indígenas, assim como é dos negros, dos trabalhadores, dos egressos de escolas públicas e de tantos outros.

Luciano (2009), pesquisador baniwa, comenta que existe a percepção, entre os indígenas, da importância de uma devida "[...] apropriação dos conhecimentos técnicos e tecnológicos que podem contribuir para a melhoria das condições de vida dos povos indígenas, impactados negativamente pela redução, invasão e destruição de seus territórios e de seus recursos naturais" (p. 32).

A universidade é entendida pelos indígenas como espaço de saber dominante que precisa ser utilizado e ressignificado para servir às suas necessidades. Entre as finalidades da formação acadêmica de profissionais indígenas está a de favorecer a preparação e o comprometimento para "[...] a promoção da qualidade de vida das suas comunidades de origem, que inclui a gestão dos territórios e o fortalecimento de suas organizações" (NASCIMENTO, BRAND e URQUIZA, 2011, p. 17).

Os acadêmicos indígenas vão para as universidades, mas não deixam de ser índios, permanecendo extremamente vinculados às suas comunidades. O kaiowá Benites (2009b), a respeito disto, diz: "o discurso que o indígena estava abandonando a aldeia não me convenceu - temos uma ligação muito forte com as nossas famílias, por isso não acredito que iremos abandoná-las" (p. 43).

Verón (2009), professor kaiowá, relata a alegria e a preocupação que sente: "alegrome por estar na universidade, mas penso também em meu povo, no confinamento em que estamos. Ainda estamos em conflitos por terras, se não as tivermos, imaginem como será a vida de nossos filhos e netos" (p. 176). Os índios preocupam-se em contribuir com suas comunidades por meio de sua formação acadêmica, pois têm uma responsabilidade social com seus povos. Isso se choca, por vezes, com a cultura individualista hegemônica na sociedade e na universidade.

No estado de Mato Grosso do Sul, segundo Nascimento, Brand e Urquiza (2011), há uma crescente procura dos índios por cursos em áreas como direito, saúde e ciências agrárias, entre outras, tendo em vista "[...] uma demanda das aldeias ou comunidades e não mais tanto de projetos pessoais de inserção fora das aldeias” (p. 20).

De acordo com Luciano (2009), os acadêmicos indígenas utilizam os conceitos e metodologias das disciplinas acadêmicas, mas é perceptível na Educação Superior um “[...] desencontro de perspectivas epistemológicas entre a racionalidade dos saberes indígenas e a racionalidade dos conhecimentos ditos científicos, de difícil equação sem uma mudança nas bases normativas e epistêmicas das disciplinas e da instituição" (p. 32).

A presença da diferença indígena na universidade pode fazer com que essa instituição incorpore saberes indígenas, questione a perspectiva de ciência asséptica e

\begin{tabular}{l|l|l|l|l|l|l} 
(C) Rev. Inter. Educ. Sup. & Campinas, SP & v.1 & n.2 & p.120-135 & out./dez. 2015 & ISSN 2446-9424
\end{tabular}


conhecimento imparcial, desvinculada das realidades de suas comunidades, e produza relações mais igualitárias com os povos indígenas.

Parcerias de comunidades indígenas com pesquisadores e instituições acadêmicas são feitas, porém, os índios contestam seu lugar habitual de meros objetos de pesquisa. Benites (2009b) expõe: "creio que a universidade pode nos ver negativa e positivamente; já demonstramos que queremos utilizá-la, por isso estamos lá” (p. 43).

Assim como os indígenas, os negros rejeitam ser concebidos somente como informantes, objetos de estudo, e reivindicam a posição de sujeitos de saberes. Pesquisadores negros, a partir de suas perspectivas, estudam as relações étnico-raciais no Brasil, falam de si mesmos, contam sua própria história, investigam as identidades negras, mas também as identidades brancas.

Verón (2009) comenta acerca da tensão vivida pelos indígenas no ambiente acadêmico: "sempre defendo em meus discursos a troca de conhecimento, embora ainda exista o medo do indígena e do não indígena, com relação à nossa presença na universidade" (p. 176).

Ocorrem conflitos culturais no ambiente universitário, causados pelas divergências de perspectivas. Nesse local, os indígenas e negros ainda são alvos de discriminações. Todavia, negros e indígenas não desistem de pintar a universidade de outras cores. Afinal, pintá-la somente de branco é incompatível com a construção de uma sociedade mais justa, solidária e democrática.

Peralta (2009), intelectual kaiowá, faz um convite e um alerta: "devemos nos recuperar do que fizeram conosco, porque nossa ciência, história, geografia e conhecimento não servem somente para nós, mas para o planeta" (p. 40). Os acadêmicos negros e indígenas estão diretamente envolvidos nas lutas pela igualdade e por um mundo melhor.

Nascimento (2009), referindo-se à sua experiência com os Kaiowá/Guarani de Mato Grosso do Sul, escreve que, para eles, “[...] a universidade é um novo território a ser conquistado, ou seja, a universidade é um caminho para construir novas relações com o Estado e com a sociedade" (p. 55). Além das vagas destinadas aos índios em cursos de graduação pelas políticas de ação afirmativa na Educação Superior, as licenciaturas indígenas nas universidades brasileiras, conquista da mobilização indígena, também instituem as marcas das diferenças indígenas na academia.

As licenciaturas indígenas provocam a necessidade das instituições que as oferecem, uma reorganização de sua estrutura curricular e a ressignificação de seus pressupostos de trabalho. Os cursos são voltados para atender às demandas de formações específicas das comunidades indígenas. Tais cursos contam com a participação das lideranças indígenas e 
funcionam também como espaços de reflexões coletivas acerca das realidades enfrentadas pelas aldeias.

As diferenças indígenas e negras nas instituições de Ensino Superior provocam tensões no espaço acadêmico relacionadas a formas alternativas de produção de conhecimento e têm oportunizado o contato mais frequente entre diferentes sujeitos e saberes. “A entrada dos indígenas na universidade tem suscitado discussões e reflexões, despertado o interesse de pesquisadores e professores para a questão indígena e instigado à proposição de projetos de pesquisa, ensino e extensão" (CREPALDE, 2009, p. 161). O interesse pela formação universitária de indígenas e a participação dos índios em seminários vêm crescendo nos últimos anos.

$\mathrm{Na}$ universidade, as diferenças indígenas têm feito pesquisadores não-indígenas (brancos e de outras identificações étnico-raciais) pensar sobre conhecimentos advindos "[...] de outras lógicas epistemológicas que não a produzida pela [eurocêntrica e branca] cultura ocidental e imposta como a condição única de compreensão e concepção de mundo" (NASCIMENTO, BRAND e URQUIZA, 2011, p. 25).

Nascimento (2014) fala de como a diferença indígena tem possibilitado pensar em práticas que procuram subverter a normatividade da academia no Programa de PósGraduação em Educação onde atua como professora:

[...] temos ousado, especificamente com relação às pesquisas de pós-graduação: permitir o texto na língua indígena (com tradução); realizar as bancas de defesas nas aldeias permitindo a apresentação do trabalho para a comunidade na língua indígena, e a última experiência que tivemos e que nos afetou muito, foi a participação de uma mestre tradicional, uma sábia da aldeia, como parte efetiva da banca, fazendo as suas considerações na língua indígena [...] e avaliando junto aos demais membros da banca (p. 39).

Os indígenas e negros estão chamando cada vez mais a atenção da academia. Todavia, ainda existem movimentos (neo)conservadores nas universidades defendendo a "alta" cultura, erudita, burguesa e branca como a única capaz de produzir conhecimentos válidos. Quando atormentada pelas diferenças desnaturalizando o alto prestígio branco, a branquidade colonizadora ${ }^{7}$ torna-se mais visível.

A diferença negra e indígena na Educação Superior, entre outras, e o interesse crescente pelas questões envolvendo as relações étnico-raciais podem contribuir para expor "[...] como a força da hegemonia branca se faz presente em discursos identitários que não mencionam raça [ou etnia] explicitamente [...]" (SOVIK, 2005, p. 167), e a branquidade colonizadora, naturalizada como padrão de normalidade, qualidade e referência mestra, que posiciona os outros na anormalidade e inferioridade.

\footnotetext{
${ }^{7}$ Resquício colonial. Discurso identitário, nem sempre explícito, que prega uma suposta supremacia branca nas relações culturais e étnico-raciais, à qual todos devem curvar-se.
}

\begin{tabular}{l|l|l|l|l|l|l} 
(C) Rev. Inter. Educ. Sup. & Campinas, SP & v.1 & n.2 & p.120-135 & out./dez. 2015 & ISSN 2446-9424
\end{tabular}


Os brancos precisam reconhecer que as desigualdades étnico-raciais que existem têm beneficiado a eles em detrimento de outros: "Nesse sentido, cabe aos brancos uma renovada reflexão sobre seu lugar na sociedade brasileira, para preceder a uma ação também de brancos contra o racismo" (SOVIK, 2005, p. 171). Pesquisadores brancos não podem mais "[...] falarem sempre entre brancos pretendendo falar por todos e para todos" (CARVALHO, 20052006, p. 100).

As diferenças negras e indígenas infiltram-se na universidade, nos saberes/poderes dominantes, e colocam a hegemonia branca em xeque, porque nos provocam a perceber e questionar "[...] uma ciência confinada, monorracial ou monoétnica que não se questiona sobre a sua participação ou conivência com a segregação ou o extermínio [...]" (CARVALHO, 2005-2006, p. 99) de maneira ainda muito forte nas instituições acadêmicas.

\section{CONSIDERAÇÕES FINAIS}

A ressignificação da universidade está relacionada a leituras diferentes feitas desse espaço e dos saberes nele produzidos pelos acadêmicos indígenas e negros. Leituras que causam impactos nas maneiras de entendermos as opressões, as discriminações e os racismos por aqueles que sentem seus efeitos mais aterradores. Negros e indígenas na academia vêm utilizando a universidade como espaço de embates contra as discriminações e para a produção de sentidos e conhecimentos úteis e comprometidos para enfrentarmos o colonizador que ainda habita em nós e entre nós.

Ressignificar é ler de outra forma, traduzir e produzir outros significados. As traduções são operações que envolvem hibridismos. Assim, os saberes da autoridade cultural, destituídos de sua presença plena (porque agregam a diferença negra e indígena), "[...] podem ser articulados com as formas de saberes 'nativos' ou confrontados com aqueles sujeitos discriminados que eles têm de governar, mas que já não podem representar" (BHABHA, 1998, p. 167). Nesses hibridismos, saberes antes negados pela sociedade branca infiltram-se na Educação Superior (local de autoridade cultural) para abalar as certezas sobre os indígenas, os negros e nós mesmos, criadas pelas verdades modernas.

A tensão na ressignificação da universidade é constante. A intenção é produzir relações acadêmicas mais igualitárias. $\mathrm{Na}$ tarefa de aprender a ouvir as diferenças indígenas e negras na academia, existem entraves referentes à nossa condição de sujeitos constituídos pela cultura moderna e branca, que se coloca como superior e universal, pois naturalizou significados e relações desiguais de poder a seu favor - e a presença de negros e indígenas na Educação Superior têm sido decisiva para superar esses entraves. 


\section{REFERENCIAS}

BACKES, José Licínio; NASCIMENTO, Adir Casaro. Aprender a ouvir as vozes dos que vivem nas fronteiras étnico-culturais e da exclusão: um exercício cotidiano e decolonial. Série-Estudos, Campo Grande, n. 31, p. 25-34, 2011.

BAUMAN, Zygmunt. Modernidade e holocausto. Rio de Janeiro: Jorge Zahar Editor, 1998.

BENITES, Eliel. Relato sobre saberes - práticas indígenas e a universidade. In: NASCIMENTO, A. C.; FERREIRA, E. L.; COLMAN, R. S.; KRAS, S. M. (Org.). Povos indígenas e sustentabilidade: saberes e práticas interculturais nas universidades. Campo Grande: UCDB, 2009a. p. 29-29.

BENITES, Eliel. Relato sobre o papel da universidade sob a ótica dos povos e acadêmicos indígenas. In: NASCIMENTO, A. C.; FERREIRA, E. L.; COLMAN, R. S.; KRAS, S. M. (Org.). Povos indígenas e sustentabilidade: saberes e práticas interculturais nas universidades. Campo Grande: UCDB, 2009b, p. 43-43.

BHABHA, Homi K. O local da cultura. Belo Horizonte: Editora UFMG, 1998.

CARDOSO, Lourenço. O branco ante a rebeldia do desejo: um estudo sobre a branquitude no Brasil. Tese de Doutorado em Ciências Sociais. Araraquara: Faculdade de Ciências e Letras da Universidade Estadual Júlio de Mesquita Filho, 2014.

CARVALHO, José Jorge. O confinamento racial do mundo acadêmico brasileiro. Revista USP, n. 68. São Paulo: USP, 2005-2006. p. 88-103.

CORREIA, Alexandre. A universidade medieval. Revista da Faculdade de Direito da Universidade de São Paulo, São Paulo, v. 45, p. 292-329, 1950.

CREPALDE, Adilson. Exposição de Adilson Crepalde. In: NASCIMENTO, A. C.; FERREIRA, E. L.; COLMAN, R. S.; KRAS, S. M. (Org.). Povos indígenas e sustentabilidade: saberes e práticas interculturais nas universidades. Campo Grande: UCDB, 2009. p. 160-163.

DERRIDA, Jacques. O olho da universidade. São Paulo: Estação Liberdade, 1999.

FRANKENBERG, Ruth. A miragem de uma branquidade não-marcada. In: WARE, V. (Org.). Branquidade: identidade branca e multiculturalismo. Rio de Janeiro: Garamond, 2004. p. 307-338.

GOMES, Nilma Lino. Intelectuais negros e produção do conhecimento: algumas reflexões sobre a realidade brasileira. In: SANTOS, B. S.; MENEZES, M. P. (Org.). Epistemologias do sul. Coimbra: Almedina, 2009. p. 419-441.

GROSFOGUEL, Ramón. Para descolonizar os estudos de economia política e os estudos póscoloniais: transmodernidade, pensamento de fronteira e colonialidade global. Revista Crítica de Ciências Sociais, Coimbra, n. 80, p. 115-147, 2008 
LANDER, Edgardo. Ciências sociais: saberes coloniais e eurocêntricos. In: LANDER, E. (Org.). A colonialidade do saber: eurocentrismo e ciências sociais. Buenos Aires: CLACSO, 2005, p. 133-163.

LUCIANO, Gersem dos Santos. O papel da universidade sob a ótica dos povos e acadêmicos indígenas. In: NASCIMENTO, A. C.; FERREIRA, E. L.; COLMAN, R. S.; KRAS, S. M. (Org.). Povos indígenas e sustentabilidade: saberes e práticas interculturais nas universidades. Campo Grande: UCDB, 2009. p. 32-39.

MUNANGA, Kabengele. Rediscutindo a mestiçagem no Brasil: identidade nacional versus identidade negra. Petrópolis: Vozes, 1999.

NASCIMENTO, Adir Casaro. Formação de professores indígenas kaiowá e guarani em Mato Grosso do Sul. In: NASCIMENTO, A. C.; FERREIRA, E. L.; COLMAN, R. S.; KRAS, S. M. (Org.). Povos indígenas e sustentabilidade: saberes e práticas interculturais nas universidades. Campo Grande: UCDB, 2009. p. 53-57. 